\title{
Bond strength between acrylic resin and maxillofacial silicone
}

\author{
Marcela Filié HADDAD'1, Marcelo Coelho GOIATO², Daniela Micheline dos SANTOS², Nádia de Marchi CREPALDI ${ }^{3}$, \\ Aldiéris Alves PESQUEIRA' ${ }^{1}$, Lisiane Cristina BANNWART ${ }^{1}$
}

\begin{abstract}
1- DDS, MSc, Department of Dental Materials and Prosthodontics, Araçatuba Dental School, Univ Estadual Paulista - UNESP, Araçatuba, SP, Brazil. 2- DDS, MSc, PhD, Professor, Department of Dental Materials and Prosthodontics, Araçatuba Dental School, Univ Estadual Paulista - UNESP, Araçatuba, $\mathrm{SP}$, Brazil.

3- DDS, Department of Dental Materials and Prosthodontics, Araçatuba Dental School, Univ Estadual Paulista - UNESP, Araçatuba, SP, Brazil.
\end{abstract}

Corresponding address: Marcelo Coelho Goiato - Faculdade de Odontologia de Araçatuba - UNESP - Departamento de Materiais Odontológicos e Prótese Rua José Bonifácio, n.1193 - Vila Mendonça - 16.015-050 - Araçatuba - SP - Brazil - Phone: (18) 3636-3246 - FAX: (18) 3636-3245 - e-mail: goiato@foa.unesp.br

Received: April 09, 2012 - Modification: August 17, 2012 - Accepted: September 17, 2012

\section{ABSTRACT}

\begin{abstract}
The development of implant dentistry improved the possibilities of rehabilitation with maxillofacial prosthesis. However, clinically it is difficult to bond the silicone to the attachment system. Objectives: This study aimed to evaluate the effect of an adhesive system on the bond strength between acrylic resin and facial silicone. Material and Methods: A total of 120 samples were fabricated with auto-polymerized acrylic resin and MDX 4-4210 facial silicone. Both materials were bonded through mechanical retentions and/or application of primers (DC 1205 primer and Sofreliner primer S) and adhesive (Silastic Medical Adhesive Type A) or not (control group). Samples were divided into 12 groups according to the method used to attach the silicone to the acrylic resin. All samples were subjected to a T-peel test in a universal testing machine. Failures were classified as adhesive, cohesive or mixed. The data were evaluated by the analysis of variance (ANOVA) and the Tukey's HSD test $(\alpha=.05)$. Results: The highest bond strength values $(5.95 \mathrm{~N} / \mathrm{mm} ; 3.07 \mathrm{~N} / \mathrm{mm} ; 4.75$ $\mathrm{N} / \mathrm{mm}$ ) were recorded for the samples that received a Sofreliner primer application. These values were significantly higher when the samples had no scratches and did not receive the application of Silastic Medical Adhesive Type A. Conclusions: The most common type of failure was adhesive. The use of Sofreliner primer increased the bond strength between the auto-polymerized acrylic resin and the Silastic MDX 4-4210 facial silicone.
\end{abstract}

Key words: Silicone elastomers. Acrylic resins. Polymethyl methacrylate. Dental implantation.

\section{INTRODUCTION}

Maxillofacial prosthesis has been used to rehabilitate mutilated patients by repairing extensive bone and soft tissues losses $6,9,11,13,20,21$. The aesthetic appearance, comfort, self-esteem as well as the quality of life of these patients have been improved with the use of facial prosthesis $6,9,11-12,14,21$.

The development of implant dentistry improved the possibilities of rehabilitation with maxillofacial prosthesis. Nowadays, the use of implants ${ }^{9,28}$ to retain maxillofacial $4,8,10,18,19$, thumb ${ }^{3}$ and digital ${ }^{10}$ prosthesis provides excellent clinical outcomes. However, clinically it is difficult to bond the silicone to the attachment system, and de-attachments have been observed $4,7,8,16,19,25,27,30$.

In order to overcome such a limitation, the association of acrylic resin and facial silicone has been proposed $3,8,10,19$. In this technique, the retention device of the implant is embedded in acrylic resin and then covered with silicone. Nevertheless, the resin/silicone bond is not safe, and the silicone may tear or separate from the resin when patients remove their prosthesis $7,8,25,27,30$.

Clinical studies have indicated the application of primers and adhesives on the resin/silicone interface to enhance the bonding between these materials. The association of polyurethane ${ }^{5}$ and acrylic resin $7,10,16,25,27,30$ with the facial silicone has been proposed. However, to the authors' best 
knowledge there is no study investigating the effect of the simultaneous application of primers and adhesives on the bond strength between autopolymerized acrylic resin and facial silicone.

Therefore, the current study aimed to investigate the bond strength between auto-polymerized acrylic resin and facial silicone as a function of mechanical retention, primers and adhesives presence. The null hypothesis is that the application of an adhesive system (primer and adhesive) on the acrylic resin with mechanical retention would increase the bond strength between the acrylic resin and facial silicone.

\section{MATERIAL AND METHODS}

\section{Specimen fabrication}

Each sample consisted of two bars of autopolymerized acrylic resin (Orto cor, VIPI, Pirassununga, SP, Brazil) and facial silicone (Silastic MDX 4-4210, Dow Corning Corporation, Midland, MI, USA). A metallic matrix with ten rectangular spaces with $75-\mathrm{mm}$ length, $10-\mathrm{mm}$ width and 3-mm thickness ${ }^{1,5,7,16,30}$ was used to fabricate the acrylic resin bars.

The auto-polymerized acrylic resin ${ }^{3,8}$ was manipulated according to the manufacturer's instructions and was poured into the metallic matrix. The matrix was closed and 1.25 tons of pressure was applied for 10 minutes with a hydraulic press (Midas Dental Products Ltd, Araraquara, SP, Brazil). Afterwards, the matrix was placed in a curing resin device (Metalvander, Piracicaba, SP, Brazil) for 20 minutes under a hydrostatic pressure of 20 pounds. The matrix was opened and the acrylic resin bars were removed. P220 sandpaper (Tigre, Rio Claro, SP, Brazil) was used as a finishing procedure.

A total of 120 acrylic resin bars were obtained, and 60 bars did not receive any mechanical retention (scratches), and the remaining bars were scratched with a number 2135 diamond bur (KG Sorensen, Barueri, SP, Brazil). The bur was placed in a high-speed hand piece, and the long axis of the bur was parallel to the bar and tilted 45 degrees in relation to the horizontal axis during the scratches fabrication. Each scratch presented the same diameter of the bur and it was performed 25 $\mathrm{mm}$ in length of the bar in the bond area between the acrylic resin and silicone. The distance of each scratch had the same diameter of the bur.

Another metallic matrix was used to fabricate the facial silicone bar and to bond the acrylic resin bar to the facial silicone bar. This matrix had ten rectangular spaces with $75 \mathrm{~mm}$ in length, $10 \mathrm{~mm}$ in width and $6 \mathrm{~mm}$ in thickness $5,7,16,25,27,30$.

Initially, the acrylic resin bars were cleaned with gauze and acetone and then placed into the matrix. An adhesive tape was positioned covering $50 \mathrm{~mm}$ in length of the acrylic resin bar (unbonded portion), and the remaining $25 \mathrm{~mm}$ length was used to bond the silicone to the acrylic resin ${ }^{5}$. The bars were divided into 12 groups according to the adhesive system used and the presence of surface scratches (Table 1).

The application of primer on the acrylic resin surface was used to enhance the adhesive penetration $7,17,25,27,30$.

Therefore, a 30-minute period was allowed after the Dow Corning 1205 Primer (Dow Corning Corporation, Midland, MI, USA) or Sofreliner Primer S (Tokuyama Corp., Taitou-ku, Tokyo, Japan) application so that the primer could react with the resin surface. Afterwards, the MDX 4-4210 facial silicone was weighed on a digital precision scale (BEL Equipamentos Analíticos, Piracicaba, SP, Brazil) and manipulated according to the manufacturer's instructions under a controlled temperature $\left(23 \pm 2^{\circ} \mathrm{C}\right)$ and humidity $(50 \pm 10 \%)$, in

Table 1- Groups division according to the presence or not of scratches, primer and adhesive

\begin{tabular}{ccccc}
\hline Group & Specimens & Scratch & Primer & Adhesive \\
\hline 1 (control) & 10 & No & No & No \\
2 & 10 & No & DC 1205 & No \\
3 & 10 & No & Sofreliner & No \\
4 & 10 & No & No & Yes \\
5 & 10 & No & DC 1205 & Yes \\
6 & 10 & No & Sofreliner & No \\
7 & 10 & Yes & DC 1205 & No \\
8 & 10 & Yes & Sofreliner & Yes \\
10 & 10 & Yes & No & Yes \\
11 & 10 & Yes & DC11205 & Yes \\
\hline
\end{tabular}


order to obtain a homogeneous mixture ${ }^{15}$.

Before placing the silicone mixture into the matrix, some groups (Table 1 ) received a thin layer of Silastic Medical Adhesive Type A (Dow Corning Corporation, Midland, MI, USA) applied directly on the primed acrylic resin surface. The silicone mixture was then used to overfill the matrix and its surface was flattened with a steeling steel spatula and its thickness was standardized. The matrix was placed in a curing resin device with 20 pounds of pressure to avoid a bubble formation in the silicone. A total of 72 hours under room temperature was allowed so the silicone polymerizes and the formaldehyde releases, following the manufacturer's instructions. After the silicone polymerization, the specimens were separated from the matrix and the adhesive tape, used to create the unbonded area of 50

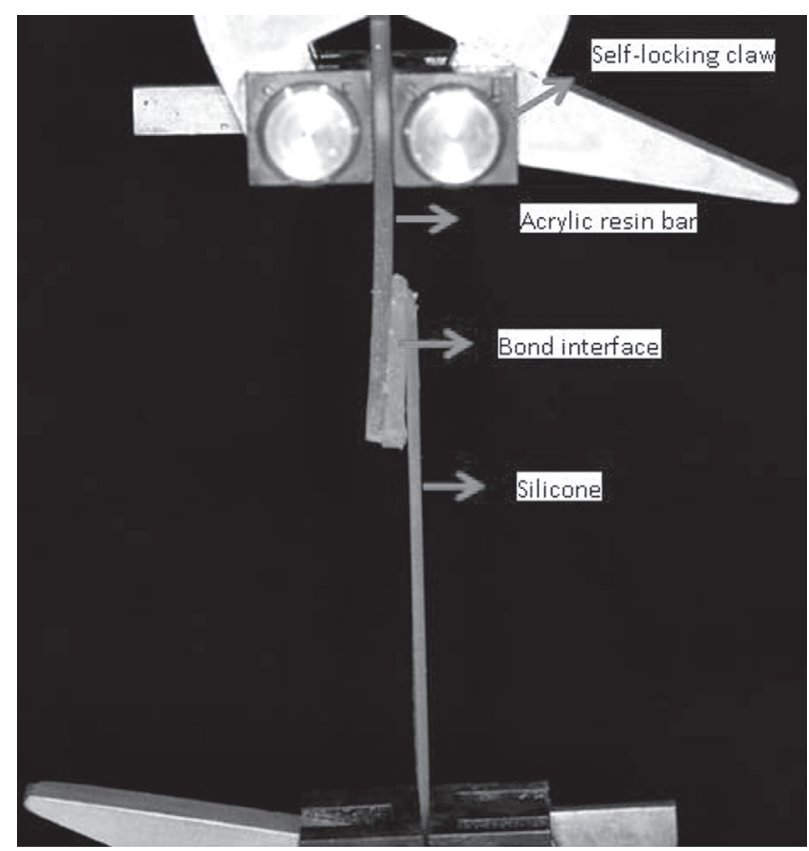

Figure 1- The silicone/acrylic specimen during the peel test $\mathrm{mm}$ in length and to allow the placement of the specimens in the universal testing machine, was removed $5,7,25,27,30$.

A total of 120 specimens were obtained and they were divided into 12 groups $(n=10)$ according to the function of scratches presence on the acrylic resin surface and adhesive system (primer and/or adhesive) type used (Table 1). The specimens were dry stored at room temperature $\left(23 \pm 1^{\circ} \mathrm{C}\right)$ for 24 hours ${ }^{17}$ and then subjected to the bond strength test.

\section{Bond strength test (T-peel test)}

An universal testing machine (Emic DL-3000, EMIC, São José dos Pinhais, PR, Brazil) was used to conduct the bond strength test at a crosshead speed of $10 \mathrm{~mm} / \mathrm{min}$ (Figure 1) 5,7,16,25,27,29,30.

The applied load and the limit load were recorded for each specimen. The T-peel strength for each specimen was determined using the average load divided by the specimen width, presented in the following formula: $\frac{F}{W} \cdot\left(\frac{1+\lambda}{2}+1\right)$ '

where, $\mathrm{F}$ is the maximum force recorded $(\mathrm{N}), \mathrm{W}$ is the width of the specimens $(\mathrm{mm})$, and $\lambda$ is the extension ratio of the silicone elastomer (the ratio of stretched to unstretched length) ${ }^{16}$.

The acrylic resin/silicone interface was visually analyzed ${ }^{17}$, and the failures were characterized as adhesive, cohesive, or mixed. Adhesive failure was defined when a complete separation of the resin and silicone occurs. Cohesive failure was characterized by the failure (i.e., tearing) occurring entirely within the silicone material. Mixed failure was characterized when both adhesive and cohesive failures are present ${ }^{5}$.

\section{Statistical analysis}

The T-peel strength data was recorded. The effects of scratch, adhesive and primer on the bond strength (interactions among these factors) were

Table 2 - Three-way analysis of variance (ANOVA) for the T-peel strength values

\begin{tabular}{cccccc}
\hline Source of variation & df & SS & MS & F & P \\
\hline Scratch & 1 & 4.008 & 4.008 & 10.630 & $0.001^{*}$ \\
Adhesive & 1 & 6.929 & 6.929 & 18.375 & $<0.0001^{*}$ \\
\hline Primer & 2 & 309.533 & 154.767 & 410.426 & $<0.0001^{*}$ \\
\hline Scratch x Adhesive & 1 & 44.243 & 44.243 & 117.328 & $<0.0001^{*}$ \\
\hline Scratch x Primer & 2 & 0.596 & 0.298 & 0.79 & 0.456 \\
Adhesive x Primer & 2 & 24.706 & 12.353 & 32.759 & $<0.0001^{*}$ \\
Scratch x Adhesive x Primer & 2 & 72.387 & 36.194 & 95.982 & $<0.0001^{*}$ \\
\hline Error & 108 & 40.725 & 0.377 & & \\
\hline Total & 119 & 503.128 & & &
\end{tabular}

*(P=.05) indicates statistically significant difference 
Table 3- T-peel strength mean values ( $\mathrm{N} / \mathrm{mm})$ and (standard deviation) for all groups

\begin{tabular}{|c|c|c|c|c|c|c|c|c|c|c|c|c|}
\hline GROUPS & 1 & 2 & 3 & 4 & 5 & 6 & 7 & 8 & 9 & 10 & 11 & 12 \\
\hline T-PEEL & 0.02 & 0.11 & 5.95 & 0.11 & 0.10 & 0.79 & 0.17 & 0.30 & 3.07 & 0.72 & 0.29 & 4.73 \\
\hline STRENGTH & $(0.00)^{A}$ & $(0.03)^{A}$ & $(1.14)^{\mathrm{B}}$ & $(0.04)^{A}$ & $(0.04)^{A}$ & $(0.26)^{A}$ & $(0.03)^{A}$ & $(0.04)^{A}$ & $(1.00)^{C}$ & $(0.10)^{A}$ & $(0.05)^{A}$ & $(1.47)^{\mathrm{D}}$ \\
\hline
\end{tabular}

Means followed by same letters did not differ among each other ( $\alpha=.05$ /Tukey's HSD test)

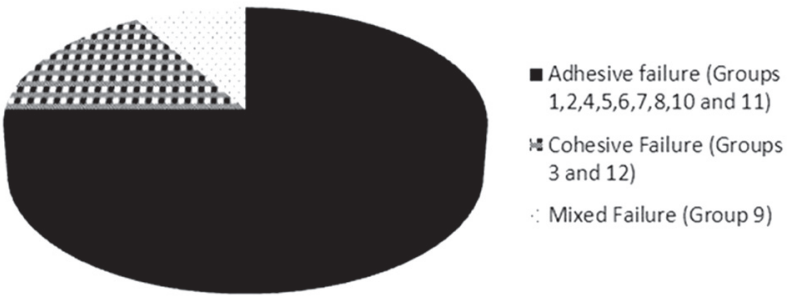

Figure 2: Type of bonding failure for all groups

analyzed by 3-way repeated-measures analysis of variance (ANOVA). The means were compared by the Tukey's HSD test $(\alpha=.05)$.

\section{RESULTS}

\section{Data are summarized in Tables 2 and 3}

The ANOVA results revealed a statistically significant difference on the T-peel strength of the specimens for all factors, except for the interaction scratch $x$ primer (Table 2).

The T-peel strength data from group 3 only exhibited a statistically-significant highest bond value in comparison to all groups (Table 3 ). While groups 3, 9 and 12 displayed the highest T-peel strength values, group 1 exhibited the lowest (Table 3 ). Most of the specimens exhibited adhesive failure and some displayed mixed failures (Figure 2).

\section{DISCUSSION}

The null hypothesis was rejected since the greatest T-peel strength values were not observed in the groups with surface scratches, and primer and adhesive applications. Three mechanisms are involved in the bond between two materials: mechanical, micromechanical and molecular adhesion $^{2}$. The mechanical bond occurs when the materials are joined by small irregularities on their surface ${ }^{2}$. The micromechanical bond is observed when a bonding agent is applied on the irregular surface of the material and an efficient micromechanical link is formed with adequate tensile strength ${ }^{2}$. Finally, the combination of physical and chemical forces between the molecules of two different materials characterizes the molecular adhesion bond ${ }^{2}$.

In the current study, different mechanisms to bond the facial silicone to the acrylic resin were used. It was possible to observe that all variables (scratches, primers and adhesives) statistically affected the T-peel strength values of the specimens, except for the scratch and primer interaction (Table $2)$. Such results were expected since several clinical studies observed bonding problems between the acrylic resin and silicone $3,8,10,19$, and several mechanisms were developed to overcome these drawbacks.

Table 3 shows that groups that received the Sofreliner primer application (Groups 3, 9 and 12) displayed a statistically higher T-peel strength value when compared to the others. Therefore, it is possible to infer that the presence of scratches did not enhance the bond strength between the silicone and acrylic resin. This may be justified by the incomplete polymerization of the silicone into the scratched area.

Furthermore, the bonding between the silicone and acrylic resin may be affected by the chemical affinity between the silicone and primers $7,17,22,25-27,30$. The chemical affinity is related to the composition of the materials used. According to the manufacturer, the auto-polymerized acrylic resin (OrtoCor) is composed by powder (polymethylmethacrylate and benzoyl peroxide) and liquid (methylmethacrylate, EDMA/Crosslink/ and an inhibitor). The MDX44210 is a two-component material. The elastomer component consists of a dimethylsiloxane polymer, reinforcing silica, and a platinum catalyst. The curing component consists of a dimethylsiloxane polymer, an inhibitor, and a siloxane crosslinking agent.

Since the composition of these two materials is different, no strong bond between them was noted when no primer and adhesive was applied. The adhesive primers have an organic solvent agent to react with the silicone and resin materials ${ }^{23,26}$, and to act as a chemical intermediate component of the silicone and the acrylic resin substrates. The hydrophilic and hydrophobic groups of primers react with the functional groups of silica ${ }^{17}$. At the same time, the activation of primers directly on the substrate surface increases the wettability of the substrate and consequently impregnates the surface layer with the polymer content ${ }^{24}$.

The results obtained herein are in accordance with those from Chang, et al. ${ }^{5}$ (2009), that investigated the bond strength between the polyurethane and facial silicone and observed a greater bond strength when the Sofreliner primer was applied on the polyurethane surface. Authors stated that 
this primer has solvent in its composition, and the precise mechanism of its action remains unknown. Silastic Medical A adhesive has no solvent in its composition. Therefore, it is possible to speculate that the solvent has an effect in increasing the bond strength between the acrylic resin and facial silicone. According to the manufacturer, the DC 1205 primer is a liquid, solvent-based, film-forming primer applied to plastics, painted surfaces, plywood, masonry, metal and other construction materials to promote adhesion of one-component silicone sealants.

Furthermore, it was observed that group 3 exhibited the greatest value of bond strength even if it had no scratches and adhesive application on the acrylic resin surface, but presented a thin layer of Sofreliner primer (Table 3).

It is interesting to note that the application of the Silastic Medical A adhesive did not improve the bond strength between the acrylic resin and facial silicone (Table 3 ). The adhesive had no complete polymerization since its surface was not exposed to the room temperature necessary to release the byproducts from the polymerization reaction as recommended by the manufacturer. This situation might explain the results obtained herein.

Concerning the failure modes, most of the specimens exhibited adhesive failure, which characterizes a complete de-bonding between the two materials tested herein. These results are not in accordance with those from Hatamleh and Watts $^{16}$ (2010) that noted greater cohesive failures. However, the authors used different silicone, acrylic resin and adhesives.

The high incidence of adhesive failures may be explained by the lack of affinity between the facial silicone and acrylic resin used herein, which characterizes a weak bonding when no primer or adhesive are applied.

Additionally, during the T-peel test, incomplete polymerization of the silicone and adhesive into the scratched areas of the acrylic resin bar was noted. The adhesive applied on the non-scratched resin bars was also not completely polymerized, maybe due to the fact that its surface was not exposed to the environment.

Groups 3 and 12 exhibited pure cohesive failure, while group 9 displayed mixed failures (Figure 2 ). These groups had the greatest values of bond strength (5.95, 4.73 and $3.07 \mathrm{~N} / \mathrm{mm}$, respectively), and received a Sofreliner primer application. Chang, et al. ${ }^{5}$ (2009) had similar results. They observed pure adhesive failure when DC 1205 primer was applied and pure cohesive failures when Sofreliner primer was used instead.

The Sofreliner primer is used to enhance the adhesion between the denture base acrylic resin and soft lining materials. Its composition and mechanism of action are unknown, but it is possible to speculate that some components of its composition are able to provide molecular adhesion between the acrylic resin and the facial silicone used herein. This may be proved since in most of the groups that had the Sofreliner primer application, the silicone was torn. In other words, the force necessary to break the resin/silicone bonding interface was higher than the tear resistance of the silicone.

Based on these in vitro results and our clinical experience, it is possible to assume that the application of Sofreliner primer on the acrylic resin devices used with maxillofacial prosthesis retained by implants can promote a safe bonding condition between the acrylic resin and facial silicone. But further laboratory studies and clinical trials are indicated. Further studies investigating the effect of the coloring agent used to tint the facial prosthesis as a function of different primers and adhesives application are warranted.

\section{CONCLUSION}

Considering the limitations of this in vitro study, it was possible to infer that the greatest bond strength between the auto-polymerized acrylic resin and the MDX 4-4210 facial silicone was observed for the groups that had no scratches on the acrylic resin bar and received the Sofreliner primer application. The adhesive failure was the most common bonding problem.

\section{ACKNOWLEDGEMENTS}

This investigation was supported by a research grant (2010/02937-1) from the Fundação de Amparo à Pesquisa do Estado de São Paulo (FAPESP).

Emerson Gomes dos Santos performed the statistical analysis.

\section{REFERENCES}

1- American Society for Testing and Materials. D1876: Standard test for peel resistance. West Conshohocken: ASTM; 2001.

2- Anusavice KJ. Phillips' science of dental materials. Philadelphia: Saunders; 1996.

3- Aydin C, Karakoca S, Yilmaz H. Implant-retained digital prostheses with custom-designed attachments: a clinical report. J Prosthet Dent. 2007;97:191-5.

4- Baima RF. Implant-supported facial prostheses. J Mich Dent Assoc. 1996;78:50-64.

5- Chang PP, Hansen NA, Phoenix RD, Schneid TR. The effects of primers and surface bonding characteristics on the adhesion of polyurethane to two commonly used silicone elastomers. J Prosthodont. 2009;18:23-31.

6- Chung RW, Siu AS, Chu FC, Chow TW. Magnet-retained auricular prosthesis with an implant-supported composite bar: a clinical report. J Prosthet Dent. 2003;89:446-9. 
7- Frangou MJ, Polyzois GL, Tarantili PA, Andreopoulos AG. Bonding of silicone extra-oral elastomers to acrylic resin: the effect of primer composition. Eur J Prosthodont Restor Dent. 2003;11:115-8.

8- Gion GG. Surgical versus prosthetic reconstruction of microtia: the case for prosthetic reconstruction. J Oral Maxillofac Surg. 2006;64:1639-54.

9- Goiato MC, Delben JA, Monteiro DR, Santos DM. Retention systems to implant-supported craniofacial prostheses. J Craniofac Surg. 2009;20:889-91.

10- Goiato MC, Garcia-Júnior IR, Magro-Filho O, Santos DM, Pellizzer EP. Implant-retained thumb prosthesis with anti-rotational attachment for a geriatric patient. Gerodontology. 2010;27:243-7. 11- Goiato MC, Haddad MF, Santos DM, Pesqueira AA, Moreno A. Hardness evaluation of prosthetic silicones containing opacifiers following chemical disinfection and accelerated aging. Braz Oral Res. 2010;24:303-8.

12- Goiato MC, Pesqueira AA, Ramos da Silva C, Gennari Filho $H$, Micheline dos Santos D. Patient satisfaction with maxillofacial prosthesis. Literature review. J Plast Reconstr Aesthet Surg. 2009;62:175-80.

13- Goiato MC, Pesqueira AA, Santos DM, Dekon SF. Evaluation of hardness and surface roughness of two maxillofacial silicones following disinfection. Braz Oral Res. 2009;23:49-53.

14- Goiato MC, Ribeiro PP, Pellizzer EP, Garcia IR Jr, Pesqueira AA, Haddad MF. Photoelastic analysis of stress distribution in different retention systems for facial prosthesis. J Craniofac Surg. 2009;20:757-61.

15- Haddad MF, Goiato MC, Santos DM, Pesqueira AA, Moreno A, Pellizzer EP. Influence of pigment and opacifier on dimensional stability and detail reproduction of maxillofacial silicone elastomer. J Craniofac Surg. 2011;22:1612-6.

16- Hatamleh MM, Watts DC. Bonding of maxillofacial silicone elastomers to an acrylic substrate. Dent Mater. 2010;26:387-95. 17- Hatamleh MM, Watts DC. Effects of bond primers on bending strength and bond of glass fibers in fiber-embedded maxillofacial silicone prostheses. J Prosthodont. 2011;20:113-9.

18- Hooper SM, Westcott T, Evans PL, Bocca AP, Jagger DC. Implant-supported facial prostheses provided by a maxillofacia unit in a U.K. regional hospital: longevity and patient opinions. J Prosthodont. 2005;14:32-8.
19- Lemon JC, Chambers MS. Locking retentive attachment for an implant-retained auricular prosthesis. J Prosthet Dent. 2002;87:336-8.

20- Leonardi A, Buonaccorsi S, Pellacchia V, Moricca LM, Indrizzi E, Fini G. Maxillofacial prosthetic rehabilitation using extraoral implants. J Craniofac Surg. 2008;19:398-405.

21- Mancuso DN, Goiato MC, Santos DM. Color stability after accelerated aging of two silicones, pigmented or not, for use in facial prostheses. Braz Oral Res. 2009;23:144-8.

22- McElroy TH, Guerra ON, Lee SA. Acetic acid vapor levels associated with facial prosthetics. J Prosthet Dent. 1985;53:86-7. 23- Minami H, Suzuki S, Ohashi $H$, Kurashige $H$, Tanaka T. Effect of surface treatment on the bonding of an auto-polymerizing soft denture liner to a denture base resin. Int J Prosthodont. 2004;17:297-301.

24- Mutluay MM, Ruyter IE. Evaluation of bond strength of soft relining materials to denture base polymers. Dent Mater. 2007;23:1373-81.

25- Polyzois GL. A comparison of microwave and dry-heat curing methods on the bond strength of silicone facial materials applied to acrylic resin. J Prosthodont. 1996;5:101-4.

26- Polyzois GL, Frangou MJ. Bonding of silicone prosthetic elastomers to three different denture resins. Int J Prosthodont. 2002;15:535-8.

27- Polyzois GL, Frangou MJ, Andreopoulos AG. The effect of bonding agents on the bond strengths of facial silicone elastomers to a visible light-activated resin. Int ] Prosthodont. 1991;4:440-4. 28- Rubenstein JE. Attachments used for implant-supported facial prostheses: a survey of United States, Canadian, and Swedish centers. J Prosthet Dent. 1995;73:262-6.

29- Stamatacos-Mercer C, Hottel TL. The validity of reported tensile bond strength utilizing non-standardized specimen surface areas. An analysis of in vitro studies. Am J Dent. 2005;18:105-8. 30- Taft RM, Cameron SM, Knudson RC, Runyan DA. The effect of primers and surface characteristics on the adhesion-in-peel force of silicone elastomers bonded to resin materials. J Prosthet Dent. $1996 ; 76: 515-8$. 